\title{
Modelling and control of an interline Current Flow Controller for meshed HVDC grids
}

\author{
Joan Sau-Bassols, Graduate Student Member, IEEE, Eduardo Prieto-Araujo, Graduate Student Member, IEEE, \\ and Oriol Gomis-Bellmunt, Senior Member, IEEE
}

\begin{abstract}
This article is focused on the modelling and control of an interline Current Flow Controller (CFC) for meshed HVDC grids. The operation states of the CFC are presented and an average model is derived. The average model is used to perform steady-state analysis on a 3-terminal meshed grid, showing the current change capabilities and the benefits on the operation area. The converter control is designed using a linearised model. The system performance of the CFC is tested by means of simulation in a 3-terminal grid and in a 5-terminal grid.
\end{abstract}

Index Terms-Meshed HVDC grid, Current Flow Controller, Power Flow Controller, DC/DC converter.

\section{INTRODUCTION}

$\mathbf{T}$ HE most optimistic future scenarios for 2020 expect to have $28 \mathrm{GW}$ of offshore wind power in Europe. Both offshore and onshore installations could provide $17 \%$ of the total energy demand in Europe [1]. Offshore wind power plants can be located far from the shore, so that the interconnection becomes challenging since $\mathrm{AC}$ transmission has important drawbacks [2]. When delivering this power from the sea to the shore, High-Voltage Direct-Current based on Voltage Source Converter (VSC-HVDC) seems to be the key technology to connect remote Wind Power Plants (WPP) as they can create an offshore AC grid and have reduced footprint compared with line-commutated-converter (LCC) HVDC [3]. The most extended interconnection is the VSC-HVDC link which consists in two VSC-HVDC terminals, one located onshore and the other offshore. As the number of VSC-HVDC links is increasing, the idea of joining them into a MTDC system has arisen [4].

MTDC poses important challenges regarding control and operation [5],[6]. Different topologies of MTDC are being considered, including meshed DC grids [7]. Having a meshed DC grid means that DC current has different paths to circulate, which are determined by cable resistances and terminal voltages. Depending on the power flow the system can have transmission bottlenecks, cable overrating and poor power flow control. In order to address these challenges, additional power devices can be introduced [8]. These elements are called Current Flow Controllers or Power Flow Controllers (PFC) and two main topologies are considered: shunt or parallelconnected and series-connected [9]. Series-connected have important advantages compared to shunt devices, for instance, they do not have to withstand the nominal voltage of the link as they are floating at the positive or negative pole. Some

Mr. Sau-Bassols, Mr. Prieto-Araujo and Dr. Gomis-Bellmunt are with the Departament d'Enginyeria Elèctrica, Centre d'Innovació Tecnològica en Convertidors Estàtics i Accionaments (CITCEA-UPC), Universitat Politècnica de Catalunya. ETS d'Enginyeria Industrial de Barcelona, Barcelona, Spain. (e-mail: joan.sau@ citcea.upc.edu)

This work has been funded by the Spanish Ministry of Economy and Competitiveness under the projects ENE2012-33043 and ENE2013-47296. shunt proposals can be seen in [10], [11]. Among seriesdevices, different topologies are being considered: switching resistances in series with cables are presented in [9]. Two six-pulse thyristor connected to a three-phase AC source is introduced in [12]. [13] shows an IGBT-based bidirectional converter connected to a external AC source. Some authors have proposed DC/DC converter which do not need from an external AC source [14], [15].

This paper provides the modelling and control of an interline DC/DC CFC for meshed HVDC grids presented in [14]. An average model is derived considering all possible operation states of the converter. They are gathered in order to exchange power between two lines. The average model is used to analyse the steady-state operation and the benefits of introducing a CFC in a 3-terminal meshed HVDC grid. Employing a linearised model of the grid and the CFC, the control is designed and system performance is tested using dynamic simulations in Matlab Simulink. In section II, an average model of the CFC is derived. Two steady-state analysis are conducted in section III. Section IV presents the linearised model of the system and control design. Section V shows the dynamic simulation results comparing the linearised average model and the switching converter model in a 3-terminal HVDC grid. Section VI presents the simulation results of the switching model of the CFC in a 5-terminal HVDC grid. Finally, section VII shows the conclusions of the work.

\section{MODEL DERIVATION}

\section{A. DC grid under study}

The following work can be applied to any meshed DC grid. For this study, a 3 terminal meshed grid with 3 nodes is used, which can be seen in Fig. 1. The DC grid is a symmetrical monopole, but this work considers only one half in order to keep the symmetry using a single power flow device. CFC is assumed to be located in node 1 . Nevertheless, it could also be placed in node 2 or 3 , given its bidirectionality.

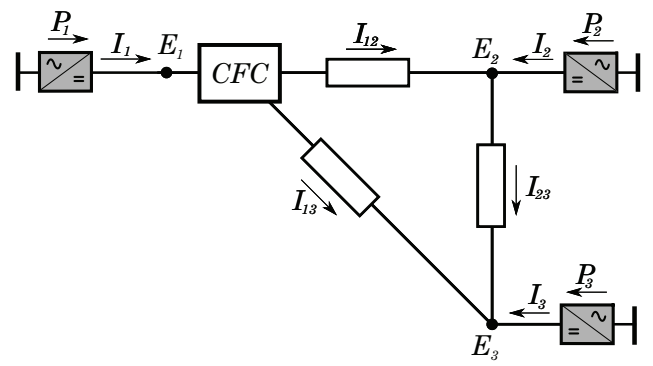

Fig. 1. 3-terminal DC grid with CFC located in node 1.

\section{B. CFC under study}

The CFC under study is a DC/DC converter connected between two cable lines. Its operation consists on exchanging 
TABLE I

CFC STATES IN POSITIVE AND NEGATIVE CURRENTS SCENARIO

\begin{tabular}{|c|c|c|c|c|r||c|c|c|c|c|c|}
\hline \multicolumn{5}{|c|}{ Positive currents scenario } & \multicolumn{5}{|c|}{ Negative currents scenario } \\
\hline State & $\mathrm{S} 2$ & $\mathrm{~S} 3$ & $\mathrm{~S} 5$ & $V_{1}$ & $V_{2}$ & State & $\mathrm{S} 1$ & $\mathrm{~S} 4$ & $\mathrm{~S} 6$ & $V_{1}$ & $V_{2}$ \\
\hline $\mathrm{a}$ & 0 & 0 & 0 & $-E$ & $-E$ & $\mathrm{i}$ & 0 & 0 & 0 & $+E$ & $+E$ \\
$\mathrm{~b}$ & 0 & 0 & 1 & $-E$ & 0 & $\mathrm{j}$ & 0 & 0 & 1 & $+E$ & 0 \\
$\mathrm{c}$ & 0 & 1 & 0 & 0 & $-E$ & $\mathrm{k}$ & 0 & 1 & 0 & 0 & $+E$ \\
$\mathrm{~d}$ & 0 & 1 & 1 & 0 & 0 & 1 & 0 & 1 & 1 & 0 & 0 \\
$\mathrm{e}$ & 1 & 0 & 0 & 0 & 0 & $\mathrm{~m}$ & 1 & 0 & 0 & 0 & 0 \\
$\mathrm{f}$ & 1 & 0 & 1 & 0 & $+E$ & $\mathrm{n}$ & 1 & 0 & 1 & 0 & $-E$ \\
$\mathrm{~g}$ & 1 & 1 & 0 & $+E$ & 0 & $\mathrm{o}$ & 1 & 1 & 0 & $-E$ & 0 \\
$\mathrm{~h}$ & 1 & 1 & 1 & $+E$ & $+E$ & $\mathrm{p}$ & 1 & 1 & 1 & $-E$ & $-E$ \\
\hline
\end{tabular}

power between these lines in order to regulate DC currents. It extracts power from one cable and it feeds the other. Thus, it applies positive voltage on one line and negative voltage on the other one. The converter is made of two H-bridges with 4 IGBTs and their antiparallel diodes (Fig. 2a). For this specific study, a simplified topology also presented in [14] is used. The two capacitors of the H-bridges are merged into a single one and two IGBTs are removed from the model leading to the converter depicted in Fig. 2b. The converter has bidirectional capability; it can deal with all possible current configurations: There are 6 possible combinations of currents $I_{1}, I_{12}$ and $I_{13}$ going in or going out of the converter. The current direction

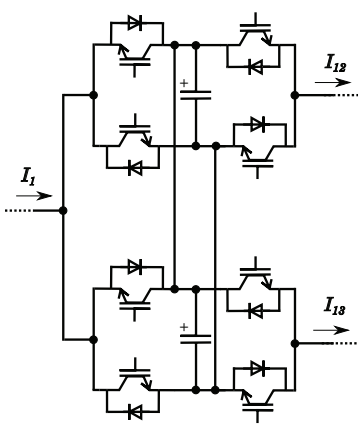

(a) $\mathrm{CFC}$ as two H-bridges.

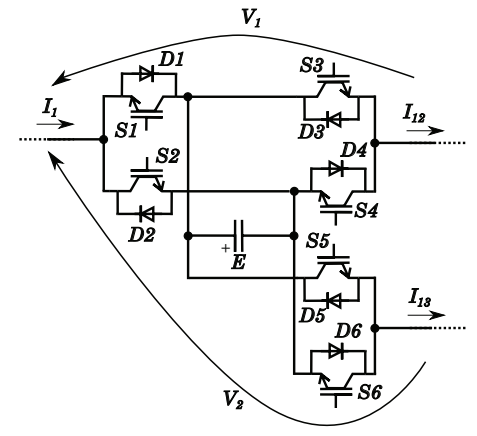

(b) CFC reduced switches topology.
Fig. 2. CFC topologies.

of each branch defines the available switches to operate. For example, if $I_{1}, I_{12}$ and $I_{13}$ are positive, the devices that are able to conduct given the current direction are: Diodes D1, D4 and D6 and switches S2, S3 and S5. When the switch of one branch is $\mathrm{ON}$, the corresponding available diode of the same branch cannot be conducting as it is reverse-biased since the capacitor voltage is always positive. Therefore, if S2 is conducting, D1 is reverse-biased and consequently in open state. Considering this scenario of current flow, the possible states concerning the available switches are summarized in Table I. Value 1 represents the switch in ON state and 0 is the notation when it is in OFF state. The capacitor voltage is represented as $E$. Table I also summarizes the operation states when the currents $I_{1}, I_{12}$ and $I_{13}$ are negative. In order to exchange power, the important states are those which are not imposing the same voltage to both lines $(b, c, f, g)$ and $(j, k, n, o)$. A possible operation of the considered $\mathrm{CFC}$ has been presented in [16] where a duty ratio is applied to several switches. However, the objective of this work is operating the CFC with the minimum required switches.

\section{Operation principle}

In this section, the operation principle of the CFC will be presented. Two current flow scenarios are considered: The first one assumes that $I_{1}$ is going out the CFC and $I_{2}$ and $I_{3}$ are entering. The second one considers the currents in opposite direction compared with the first case. This analysis can be extended to the rest of possible current configurations. In order to share power within the two lines, the converter capacitor should be charged and discharged continuously. Only 4 states (two pairs) from the group of 8 for each current configuration are used to control the device in such conditions: $(\mathrm{b}, \mathrm{c}, \mathrm{f}, \mathrm{g})$ for positive current scenario and $(\mathrm{j}, \mathrm{k}, \mathrm{n}, \mathrm{o})$ for negative current scenario. Those states are the ones which enable the charge of the capacitor using one current line and the discharge employing another one. They are used in pairs of two states, one state charges the capacitor and the other discharges it. One pair limits the current through one line and the other pair increases current through the same line. Both pairs have a positive voltage in the capacitor, however one pair applies positive voltage in one line and the other applies negative voltage in the same line (c with $\mathrm{g}, \mathrm{b}$ with $\mathrm{f}$ ). Both pairs can be seen in Fig. 3 for each scenario. The following analysis is performed considering the first scenario with positive currents. It must be noticed that the difference between the two states of the same pair is only the switch S2. Using the commutation of that switch is possible to increase one line current $\left(I_{12}\right)$ and decrease the other $\left(I_{13}\right)$ (Pair A). If the reverse effect wants to be achieved, the procedure should be changing the states of switches S3 and S5 and keep operating with $\mathrm{S} 2$, what is equivalent as working with Pair B. Below, the analytical analysis of the converter is performed for the two pairs of states presented before. Then, the conclusions and the average model can be extended to the whole range of current configurations. The duty cycle of switch S2 for pair A and B are defined as (1).

$$
D_{s 2 A}=\frac{t_{s 2 A}}{T}, \quad D_{s 2 B}=\frac{t_{s 2 B}}{T}
$$

The average current through the capacitor can be calculated as a function of the line currents and the duty cycles for each pair (2) and (3).

$$
\begin{aligned}
\bar{I}_{c A} & =\frac{1}{T} \int_{0}^{T} i_{c A} d t=\frac{1}{T}\left(-I_{12} t_{s 2 A}+I_{13}\left(T-t_{s 2 A}\right)\right) \\
& =-I_{12} D_{s 2 A}+I_{13}\left(1-D_{s 2 A}\right) \\
\bar{I}_{c B} & =\frac{1}{T} \int_{0}^{T} i_{c B} d t=\frac{1}{T}\left(-I_{13} t_{s 2 B}+I_{12}\left(T-t_{s 2 B}\right)\right) \\
& =-I_{13} D_{s 2 B}+I_{12}\left(1-D_{s 2 B}\right)
\end{aligned}
$$

In order to ensure that the average capacitor voltage is constant in steady state, both capacitor currents from equations (2), (3) must be zero. This fact shows that the duty cycle for each pair is going to be determined by line currents relation. The relation derived from equations (2) and (3) is shown in expression (4).

$$
D_{s 2 A}=\frac{I_{13}}{I_{12}+I_{13}}=\frac{I_{13}}{I_{1}}, \quad D_{s 2 B}=\frac{I_{12}}{I_{12}+I_{13}}=\frac{I_{12}}{I_{1}}
$$

In order to gather both duty cycles in the whole average model, a new one is defined as a relation between DC currents (5). 
Pair A
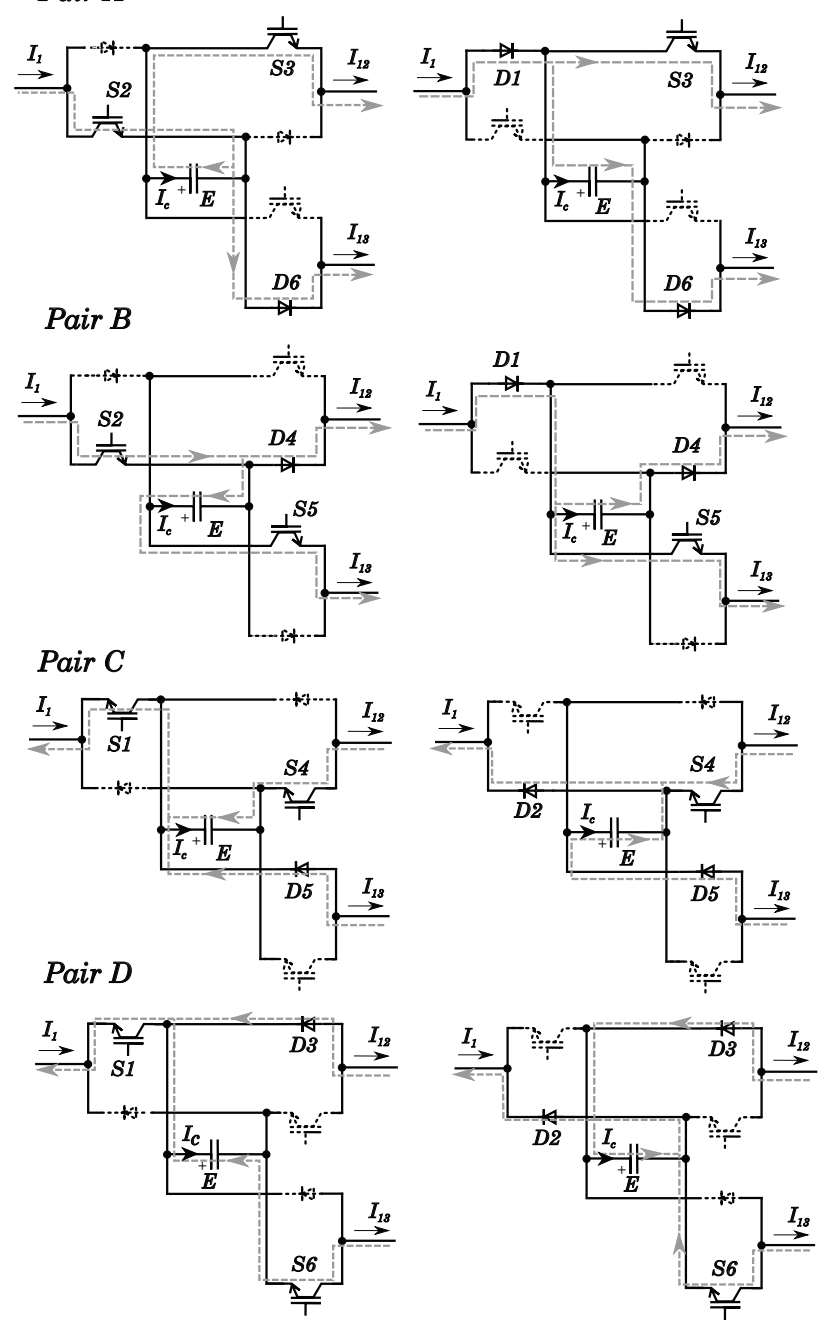

Fig. 3. Pairs A, B, C and D.

$$
D=\frac{I_{12}}{I_{1}}=D_{s 2 B}=\left(1-D_{s 2 A}\right)
$$

The average voltages applied by the CFC with $I_{1}, I_{12}$ and $I_{13}$ positive are (6), and (7) working with pair A.

$$
\begin{gathered}
\bar{V}_{1 A}=\frac{1}{T} \int_{0}^{T} v_{1 A} d t=\frac{1}{T}\left(\bar{E} t_{s 2 A}\right)=D_{s 2 A} \bar{E}=(1-D) \bar{E} \\
\bar{V}_{2 A}=\frac{1}{T} \int_{0}^{T} v_{2 A} d t=\frac{1}{T}\left(-\bar{E}\left(T-t_{s 2 A}\right)\right) \\
=-\left(1-D_{s 2 A}\right) \bar{E}=-D \bar{E}
\end{gathered}
$$

And (8) and (9) working with B.

$$
\begin{gathered}
\bar{V}_{1 B}=\frac{1}{T} \int_{0}^{T} v_{1 A} d t=\frac{1}{T}\left(-\left(T-t_{s 2 B}\right) \bar{E}\right. \\
=-\left(1-D_{s 2 B}\right) \bar{E}=-(1-D) \bar{E} \\
\bar{V}_{2 B}=\frac{1}{T} \int_{0}^{T} v_{2 B} d t=\frac{1}{T}\left(t_{s 2 A} \bar{E}\right)=D_{s 2 B} \bar{E}=D \bar{E}
\end{gathered}
$$

The same analysis can be done considering currents $I_{1}, I_{12}$ and $I_{13}$ negative. In that scenario, the available switches and diodes to conduct are: S1, S4, S6, D2, D3 and D5. The difference between the two states of the same pair is also the switch state that gathers all the current from two lines, S1. The voltage
TABLE II

CFC VOLTAGES APPLIED FOR EACH PAIR OF OPERATION STATES

\begin{tabular}{|c||c|c|}
\hline Pair & $\bar{V}_{1}$ & $\bar{V}_{2}$ \\
\hline A & $(1-D) \bar{E}$ & $-D \bar{E}$ \\
B & $-(1-D) \bar{E}$ & $D \bar{E}$ \\
C & $-(1-D) \bar{E}$ & $D \bar{E}$ \\
D & $(1-D) \bar{E}$ & $-D \bar{E}$ \\
\hline
\end{tabular}

applied on each line is positive or negative depending on the state of switches S4 and S6. In order to exemplify the operation of the CFC, Fig. 4 shows the operation principle working with pair A. The variables $E, I_{c}, V_{1}$ and $V_{2}$ are depicted considering constant line currents $\left(I_{12}=1.5 \mathrm{kA}\right.$ and $\left.I_{13}=0.7 \mathrm{kA}\right)$. From
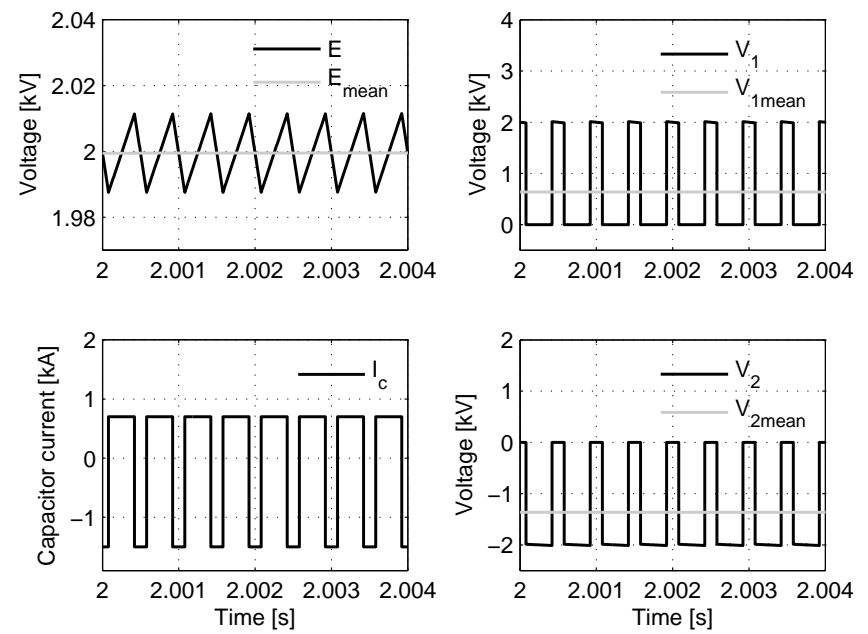

Fig. 4. $E, I_{c}, V_{1}$ and $V_{2}$ working with pair A.

the previous analysis the voltage ripple can be deduced and it is given by equation (10).

$$
\Delta E_{\text {ripple }}=\frac{I_{12} I_{13}}{f C\left(I_{12}+I_{13}\right)}
$$

where $\Delta E_{\text {ripple }}$ is the voltage ripple of the capacitor, $f$ is the switching frequency of the $\mathrm{CFC}$ and $C$ is the CFC capacitance.

\section{CFC average model}

In this section an average model for the CFC is derived. The voltages applied by the converter considering pairs $\mathrm{A}, \mathrm{B}$, $\mathrm{C}$ and D are shown in table II. Pairs A and B are applying opposite effects on the DC grid, the same happens with $\mathrm{C}$ and $\mathrm{D}$. Whereas one increases $I_{12}$, the other rises the value of $I_{13}$. Despite this fact, it is interesting to notice that voltages applied by the CFC have the same expression for both pairs (in both scenarios) with the difference of a sign. $E$ must be always positive because of the inherent functionality of the device. When deriving an average model for the 4 pairs considered before, a restriction of positive value should be placed on variable $E$. However, instead of restricting its value, it is chosen to allow negative values and using the equivalent model of pair A and D. With this consideration, when solving the system equations, $E$ will get a negative value when the opposite effect of pair A or D is expected. The negative value is not a real magnitude, it simply means that the CFC is working with pair $\mathrm{B}$ or $\mathrm{C}$ and the real average voltage of the capacitor is $|E|$. Following this procedure, an equivalent model for the two current scenarios considered is derived. It 
includes two voltage sources in series with line cables. The values of these voltage sources $V_{1}$ and $V_{2}$ are:

$$
V_{1}=(1-D) \bar{E} \quad V_{2}=-D \bar{E}
$$

This model is illustrated in Fig. 5. This average model for two current flow configurations can be extended for all the possible current combinations (six possibilities) performing the same analysis as before. Then, a new duty cycle (line current relation) to represent each couple of voltage sources must be defined. The global average model for a CFC located in one node capable of operating with all current flow combinations can be made of three couples of voltage sources.

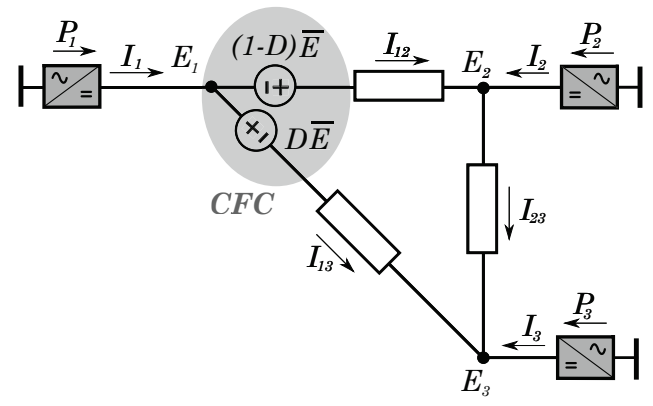

Fig. 5. 3 terminal DC grid with a CFC average model in node 1 .

\section{STEADY STATE ANALYSIS}

In this section the influence of the CFC among grid currents is analysed by means of its average model. Therefore, two steady state analysis are conducted: Current and voltage range and Operation range. Both analysis consider the node 1 as a slack bus while the other nodes are operating in constant power mode. The general parameters of the system are listed in table V. Cable parameters are extracted from [17] for a DC voltage of $\pm 200 \mathrm{kV}$. In order to address both analysis, some considerations on system and CFC limitations must be taken into account. Firstly, a maximum current limitation through cables must be considered. It is obtained from [17] and it corresponds to $2 \mathrm{kA}$. The power limitation is derived considering that any converter station can absorb the maximum current from two cables, which leads to a node current limitation of 4 $\mathrm{kA}$ and power node limitation of $1600 \mathrm{MW}$. A DC voltage variation of $\pm 5 \%$ is considered for any converter station. Finally, a limitation on the CFC voltage must be considered. A higher voltage allows higher current changes, nonetheless it also increases the device cost as more IGBT must be connected in series to withstand that voltage. For this work, a value of $4 \mathrm{kV}$ is considered for CFC maximum voltage, in order to be able to build the mentioned CFC with one or two IGBTs in series for each switch.

\section{A. Current and voltage range analysis}

This analysis performs a duty cycle sweep and system equations are solved for all its range (0-1). It plots graphics about the variables in the system: Node and line currents, node voltages and CFC capacitor voltage and node powers and CFC power as a function of the duty cycle. The restrictions concerning system variables plotted as horizontal lines are: Node current limitation, node voltage limitation and node power limitation. Line current limitation and CFC capacitor voltage are depicted as vertical lines. Vertical and horizontal lines define the operation area of the CFC. Results are exhibited working with two pairs of CFC states (equivalent to the model of a couple of voltage sources). The powers delivered for terminal 2 and 3 are $400 \mathrm{MW}$ and $800 \mathrm{MW}$, respectively and the CFC is working with pair C and D. In all of the following graphics horizontal dashed lines set the maximum value of the magnitude which is being plotted. Vertical dotted line shows the current relation in neutral state, when no CFC is operating. Greater duty cycles correspond to states of pair $\mathrm{C}$ and lower ones represent states of pair D since different pairs have opposite effects among currents within the DC grid. Vertical dash-dot line illustrates the global duty cycle where capacitor voltage is exceeded. When one of the line currents exceeds the maximum rating of the DC cable, a vertical dashed line is used to show that duty cycle. Finally, the possible region of operation is shown in shaded grey area. $D=0$ means that all current flows through cable 13 and $D=1$ all current flows through cable 12 . Line and node currents

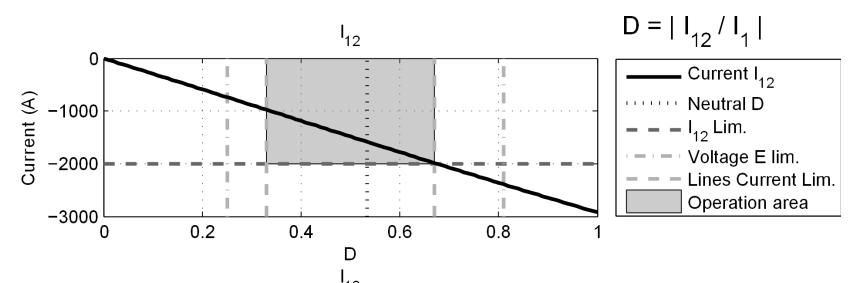
$\mathrm{I}_{13}$
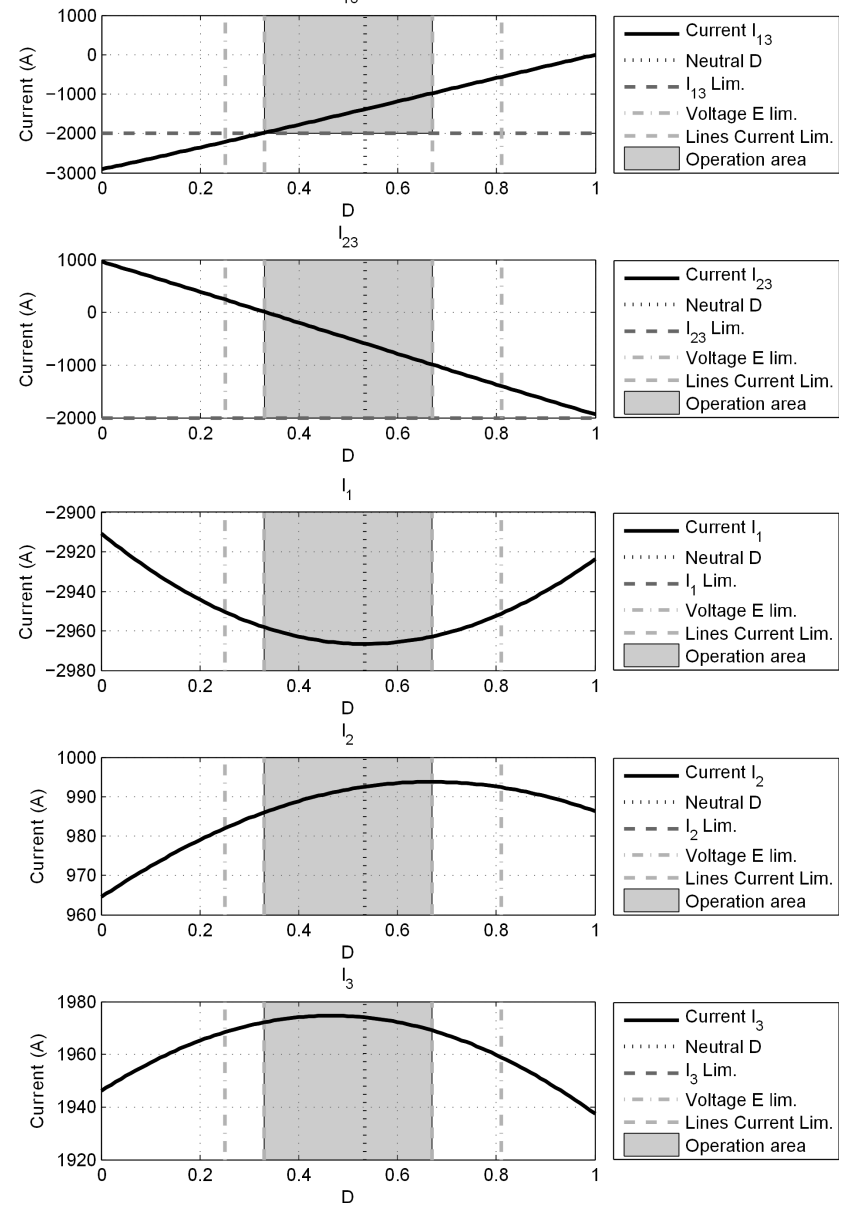

Fig. 6. Line and node currents.

evolution while operating the CFC device are depicted in Fig. 
6. It can be seen that the CFC has a large impact in the line currents, with few $\mathrm{kV}$, current can be changed in terms of hundreds of amperes. Edge duty cycles are not allowed as line current limits are exceeded and so it is capacitor voltage. For this specific scenario, the most restrictive limitation is the rating of DC cables. On the other hand, node currents suffer small variations compared to line currents. Node voltages are depicted in Fig. 7. $E_{1}$ is completely constant since it acts as slack bus. $E_{2}$ and $E_{3}$ are slightly higher than the nominal value as they are delivering constant power into the DC grid. The effects due to the CFC are small variations in node voltages of a few $\mathrm{kV}$ inside the operation area. In this graphic, CFC capacitor voltage is also shown. The real voltage of the capacitor is plotted, equivalent to the absolute value of the variable $E$ in the average model implemented. The line current limit is exceeded before reaching the maximum voltage value.
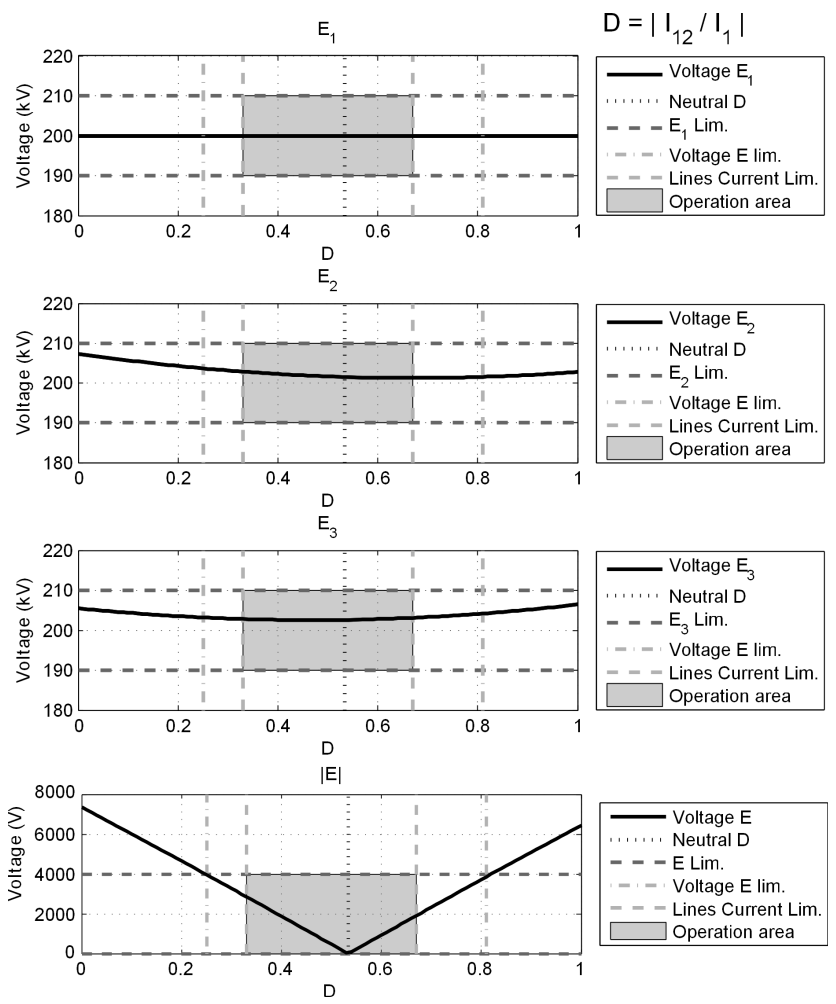

Fig. 7. Node voltages and CFC capacitor voltage.

Fig. 8 shows the total power extracted or injected in each node terminal and the CFC power. Powers from node 2 and node 3 are constant, $400 \mathrm{MW}$ and $800 \mathrm{MW}$, respectively. Regarding power extracted by node 1 , there is a small variation due to the DC grid losses (losses from the converters are not considered). The point where losses are the lowest is when the neutral duty cycle is applied, equivalent to have no CFC. For this duty cycle, the power extraction of node 1 has the maximum value. The power of the CFC starts to increase when rising the voltage, however, for edge duty cycles the current through one of the lines becomes very small and power is reduced.

\section{B. Operation range analysis}

In this section the system is analysed in terms of its operational area. A power sweep for both power of node $2\left(P_{2}\right)$ and node $3\left(P_{3}\right)$ is carried out. For each couple of power values the equations of the system are solved and the
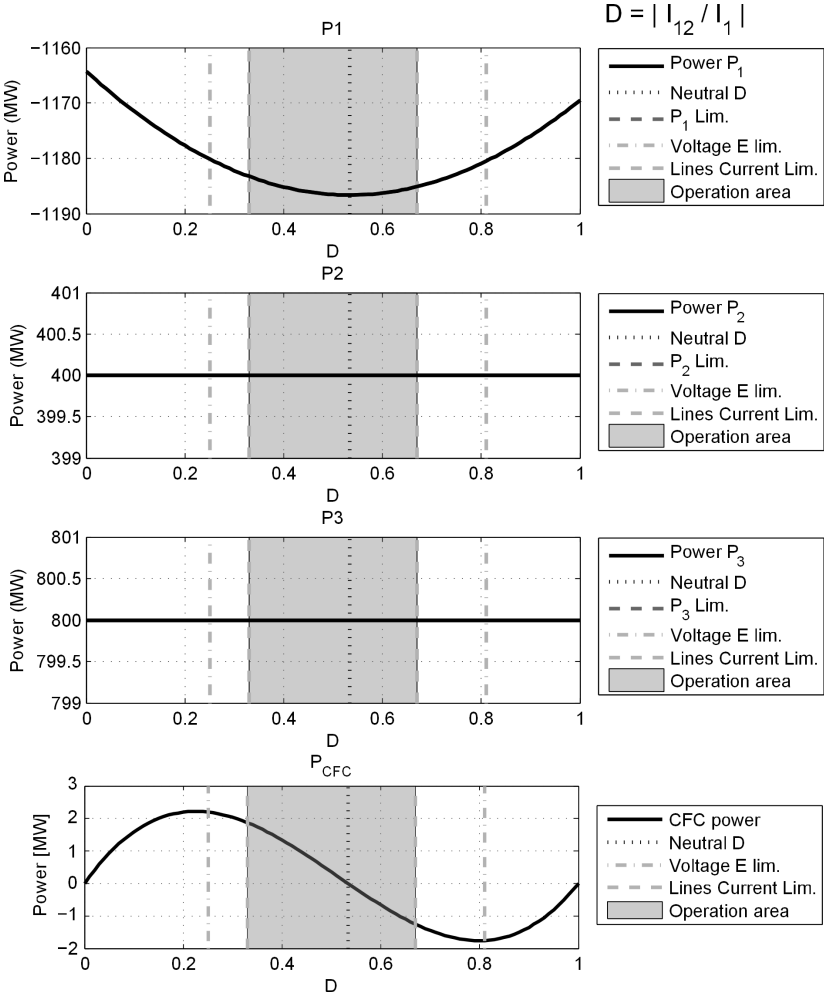

Fig. 8. Node powers and CFC power.

solution is depicted in Fig. 9 with different colors depending on the limitations that are exceeded. Horizontal axis of Fig. 9 shows power of node 2 and vertical axis shows power of node 3 . If line currents are below the limitations, the CFC is not necessary to keep the system under the operation limits. This region where the CFC is not needed is depicted with lightest grey color. The border of this region is given by black lines which show the line current that is exceeded. The main application of the CFC is to drive part of the current through other lines that are not overloaded. If one of the line currents is exceeded, the system is solved again introducing the equations of the $\mathrm{CFC}$ for any of the 6 possible current configurations. If the $\mathrm{CFC}$ is able to reduce the current through the overloaded line, the points are depicted in different tones of grey. The different tones of grey indicate the average voltage of the CFC that is required to produce such effect in the DC grid. The darker the grey is, the higher the required voltage of the CFC. As mentioned before, the maximum voltage for the $\mathrm{CFC}$ is set at $4 \mathrm{kV}$, however, several maximum values of voltage are also depicted in order to show its effect. The higher the voltage limitation, the higher the enlargement of the operation area. Several CFC maximum voltages with its associated increase of the operation area are listed in table Table III. It is interesting to note that for a certain maximum voltage, there is no improvement of the operation area because the limitation on node currents is exceeded. In this case of study, the node current limitation, which is equivalent to the power limitation of the converter stations, sets the maximum possible operation area of the system. This fact is according with the CFC specifications, as if the power of one station is exceeded, the CFC has no capability to solve the problem even if CFC maximum voltage is increased. There are two regions in the upper-left side and lower-right side that deserve 
TABLE III

OPERATION AREA INCREASE FOR DIFFERENT CFC VOLTAGES

\begin{tabular}{|c||c|c|c|c|c|c|}
\hline Maximum voltage E [kV] & 1 & 2 & 3 & 4 & 5 & 6 \\
\hline Operation area increase (\%) & 14 & 23 & 29 & 32 & 34 & 34 \\
\hline
\end{tabular}

some consideration. They are named No-Possible-Operation (NPO). In those points, nearly all power flow goes through line $I_{23}$, but CFC is located between line 12 and 13. In this case node 1 , practically does not absorb or inject power, $I_{1} \approx 0$. It means that small current goes through the device. When there is low current through the CFC, its capability to apply voltages and affect currents is drastically reduced. It is an important limitation to bear in mind when choosing the location of the $\mathrm{CFC}$ device in the $\mathrm{DC}$ grid.

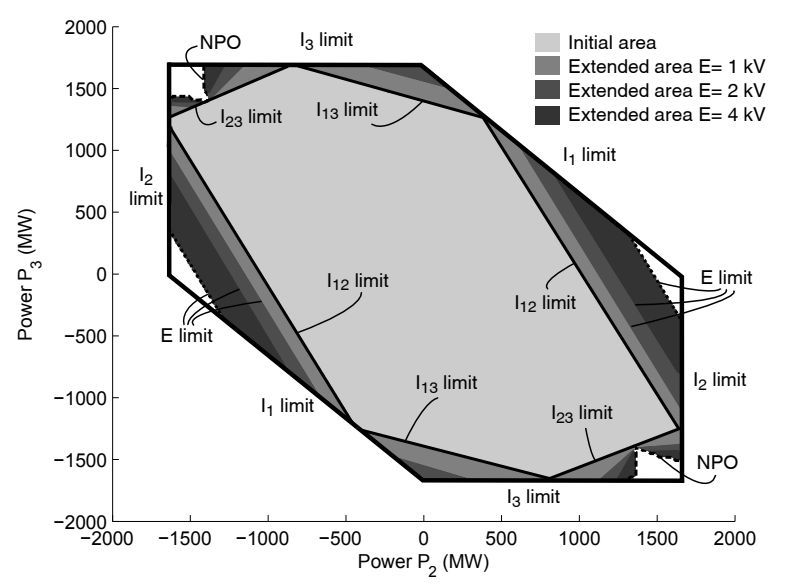

Fig. 9. Operation area.

\section{CONTROL DESIGN}

In this section the state-space representation of the meshed DC grid and the CFC is obtained. The procedure to obtain a linear model of the DC grid and the CFC is detailed. After analysing its stability the linearised model is used in order to address control design. The whole system is clearly non-linear due to the duty cycle relation imposed by the CFC. Only the DC part of the system is considered for control design and it is depicted in Fig. 10. Cables are modelled as $T$-equivalent in simulations, nevertheless the cable capacitance is neglected to derive the linearised model due to its reduced value. The DC parts of each VSC are modelled by means of its average model. The capacitor at each node is the power converter capacitance. The model is linearised as [18]:

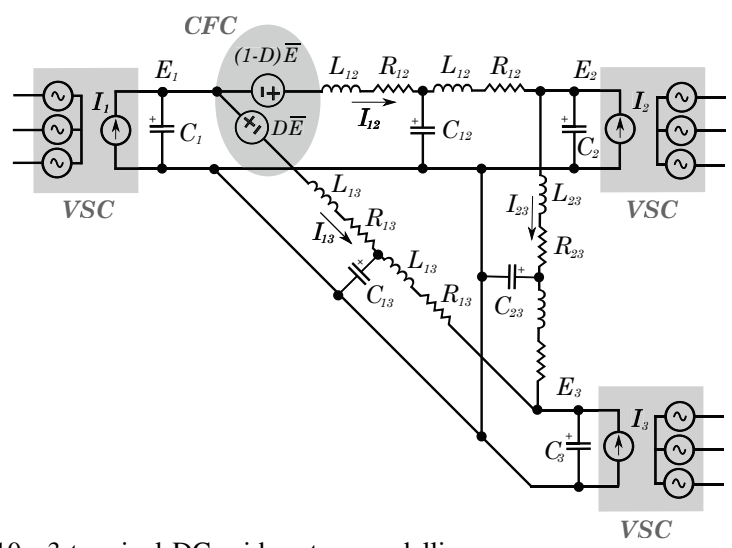

Fig. 10. 3-terminal DC grid system modelling.

$$
X \approx X_{0}+\Delta X
$$

where $X$ is a general variable, $X_{0}$ is its linearisation point and $\Delta X$ is the increment over the linearisation point. Terminal 1 is considered to be operating as a constant power injection node (13).

$$
I_{1}=\frac{P_{1}}{E_{1}}
$$

where $P_{1}$ is the power injected into the DC grid, $E_{1}$ is the measured DC voltage and $I_{1}$ is the DC current. Node 2 and 3 are performing droop [19]. The equations describing its behaviour are the following ones:

$$
I_{2}=k_{2}\left(E_{2}^{*}-E_{2}\right), \quad I_{3}=k_{3}\left(E_{3}^{*}-E_{3}\right)
$$

where, $I_{2}$ and $I_{3}$ are the node currents, $E_{2}$ and $E_{3}$ are the measured DC voltages, $E_{2}^{*}$ and $E_{3}^{*}$ are the voltage references and $k_{2}$ and $k_{3}$ are the droop constants. CFC applied voltages must be also added into the linearised model. The differential equations describing the linearised DC grid with the CFC are (15)-(21):

$$
\begin{gathered}
\frac{d \Delta E_{1}}{d t}=\frac{1}{C_{1}}\left(\frac{\Delta P_{1}}{E_{10}}-\frac{\Delta E_{1} P_{10}}{E_{10}^{2}}-\Delta I_{12}-\Delta I_{13}\right) \\
\frac{d \Delta E_{2}}{d t}=\frac{1}{C_{2}}\left(-k_{2} \Delta E_{2}+\Delta I_{12}-\Delta I_{23}\right) \\
\frac{d \Delta E_{3}}{d t}=\frac{1}{C_{3}}\left(-k_{3} \Delta E_{3}+\Delta I_{13}+\Delta I_{23}\right) \\
\frac{d \Delta I_{12}}{d t}=\frac{1}{L_{12}}\left(\Delta E_{1}-\Delta E_{2}-R_{12} \Delta I_{12}-\left(D_{0}-1\right) \Delta E-E_{0} \Delta D\right) \\
\frac{d \Delta I_{13}}{d t}=\frac{1}{L_{13}}\left(\Delta E_{1}-\Delta E_{3}-R_{13} \Delta I_{13}-D_{0} \Delta E-E_{0} \Delta D\right) \\
\frac{d \Delta I_{23}}{d t}=\frac{1}{L_{23}}\left(\Delta E_{2}-\Delta E_{3}-R_{23} \Delta I_{23}\right) \\
\frac{d \Delta E}{d t}=\frac{1}{C}\left(\left(D_{0}-1\right) \Delta I_{12}+D_{0} \Delta I_{13}+\left(I_{120}+I_{130}\right) \Delta D\right)
\end{gathered}
$$

where, $E_{i}$ is the DC voltage of node i, $I_{i}$ is the current of node $\mathrm{i}, I_{i j}$ is the current from node $\mathrm{i}$ to $\mathrm{j} . L_{i j}$ is half of the cable inductance from node $\mathrm{i}$ to $\mathrm{j}, R_{i j}$ is half of the cable resistance from node $\mathrm{i}$ to $\mathrm{j} . C_{i}$ is the power converter capacitance at node. $C$ is the CFC capacitance, $E$ is the CFC voltage and $D$ the duty cycle of the CFC. Next, the linearised state-space representation of the DC grid is described (22).

$$
\frac{d \Delta x}{d t}=\mathbf{A} \Delta x+\mathbf{B} \Delta u
$$

where $\mathbf{A}$ and $\mathbf{B}$ are:

$$
\begin{gathered}
\mathbf{A}=\left(\begin{array}{ccccccc}
-\frac{P_{10}}{C_{1} E_{10}^{2}} & 0 & 0 & -\frac{1}{C_{1}} & -\frac{1}{C_{1}} & 0 & 0 \\
0 & -\frac{k_{2}}{C_{2}} & 0 & \frac{1}{C_{2}} & 0 & -\frac{1}{C_{2}} & 0 \\
0 & 0 & -\frac{k_{3}}{C_{3}} & 0 & \frac{1}{C_{3}} & \frac{1}{C_{3}} & 0 \\
\frac{1}{L_{12}} & -\frac{1}{L_{12}} & 0 & -\frac{R_{12}}{L_{12}} & 0 & 0 & \frac{1-D_{0}}{L_{12}} \\
\frac{1}{L_{13}} & 0 & -\frac{1}{L_{13}} & 0 & -\frac{R_{13}}{L_{13}} & 0 & \frac{-D_{0}}{L_{13}} \\
0 & \frac{1}{L_{23}} & -\frac{1}{L_{23}} & 0 & 0 & -\frac{R_{23}}{L_{23}} & 0 \\
0 & 0 & 0 & \frac{D_{0}-1}{C} & \frac{D_{0}}{C} & 0 & 0
\end{array}\right) \\
\mathbf{B}=\left(\begin{array}{ccc}
\frac{1}{C_{1} E_{10}} & 0 \\
0 & 0 \\
0 & 0 \\
0 & -\frac{E}{L_{12}} \\
0 & -\frac{E}{L_{13}} \\
0 & \frac{I_{120}+I_{130}}{C}
\end{array}\right)
\end{gathered}
$$


and $\Delta x$ is the linearised state vector and $\Delta u$ i the input vector, (25) and (26) respectively.

$$
\begin{gathered}
\Delta x=\left(\Delta E_{1}, \Delta E_{2}, \Delta E_{3}, \Delta I_{12}, \Delta I_{13}, \Delta I_{23}, \Delta E\right) \\
\Delta u=\left(\Delta P_{1}, \Delta D\right)
\end{gathered}
$$

A linearised model gives similar results to the detailed model when the system is working close the linearisation point. If the point where the system works is far from the linearisation point, the two models may diverge. The control strategy is presented for the linearisation point of pair B. Though, the same methodology is also applied for the linearisation point of pair A. Based on the linearised state space, a transfer function $G(s)$ relating the duty cycle of the converter $D$ and the current $I_{12}$ is obtained. The frequency response of this transfer function is depicted in Fig. 11 showing different gain peaks that must be taken into account in the controller design stage. These large peaks are consequence of the resonances between the inductance of the cables and capacitance of nodes and cables. Initially, two control structures are considered: a single PI and a PI controller in series with a second order compensator to damp the system oscillations. Both controllers are:

$$
K_{P I}(s)=\frac{k_{p} s+k_{i}}{s} \quad K_{C}(s)=k_{c} \frac{\left(s+z_{1}\right)\left(s+z_{2}\right)}{\left(s+p_{1}\right)\left(s+p_{2}\right)}
$$

where, $K_{P I}(s)$ and $K_{C}(s)$ are the transfer functions of the PI and the compensator, respectively. Fig. 12 depicts the control scheme with the PI and second order compensator approach. Regarding the closed loop control, the system time response is set to $150 \mathrm{~ms}$, assuming a first order time response [20]. The desired time response must be at least 10 times slower than the switching frequency of the CFC $(0.5 \mathrm{~ms})$ and fast enough to provide a reasonable system response. Then, a combined design of the PI and the compensator is carried out based on a frequency domain analysis. Fig. 13 shows the bode diagram representation of the controllers. Having large gain peaks in open loop (Fig. 11) is not desirable as they can cause oscillatory behaviour in closed loop. The PI controller does not apply gain reduction at the resonance frequencies, thus a second order compensator in series is used for control design [21]. Besides, some additional considerations regarding device limits must be taken into account. Considering the previous control scheme, the physical system cannot apply duty cycles higher than 1 or lower than 0 . For this reason, the control action must be limited in order to have the output of the controller between these values for any possible current reference. The transfer function that relates control action with input reference is $K S(s) ; S(s)$ is the sensibility transfer function and $K(s)$ is the transfer function of the controller (28).

$$
K S(s)=S(s) K(s)=\frac{K(s)}{1+G(s) K(s)}
$$

The maximum gain for any frequency is obtained from the maximum input reference $\left(I_{\max }\right)$ and the acceptable variation of the duty cycle $\left(D_{v a r}\right)$. Equation (29) gives the maximum gain for $K S(s)$.

$$
\|K S(s)\|_{\max }=\frac{D_{\text {var }}}{I_{\max }}=\frac{1}{2000}=-66.02 d B
$$

TABLE IV

CONTROLLER PARAMETERS

\begin{tabular}{|l||c|c|c|c|c|c|}
\hline & $k_{p}$ & $k_{i}$ & $k_{c}$ & $z_{1,2}$ & $p_{1}$ & $p_{2}$ \\
\hline Pair A & 0.0003 & 0.0023 & 12.86 & $-2.33 \pm j 9.49$ & -79.89 & -8.70 \\
\hline Pair B & 0.009 & 0.0037 & 0.33 & $-2.48 \pm j 9.50$ & -157.52 & -0.41 \\
\hline
\end{tabular}

Fig. 14 depicts the frequency response of $K S(s)$ for different controller options. Considering a PI or a PI and compensator it is not possible to achieve a gain lower than $-66.02 \mathrm{~dB}$. For this reason a low pass filter is included in series with the PI and the compensator in order to damp the gain at high frequencies. The low pass filter has the structure of (30).

$$
K_{L P}(s)=\frac{1}{\tau+1}
$$

Fig. 14 shows the frequency response for different time constants $\tau$. The low pass filter must be chosen to provide a gain lower than the maximum but also to be fast enough not to disturb the time response of the closed loop system. Time constant of the low pass filter is set to $\tau=0.05 \mathrm{~s}$ because it is the fastest time constant that provides a gain lower than $-66.02 \mathrm{~dB}$. Fig. 15 shows the frequency and time response of the closed loop transfer function of the system. Three approaches are considered: single PI, PI+compensator and PI+compensator+LP filter. Fig. 15a shows that the approaches with the compensator are able to damp the gains peaks. All controllers show $0 \mathrm{~dB}$ gain at zero frequency, which means that the control is able to track DC current references. In order to validate the controller, the control system response for a step current reference input $I_{12}$ is represented in Fig. $15 \mathrm{~b}$ for all control approaches. The designed controllers are able to track the current reference, without steady state error in the specified time. The system without compensator has large oscillations due to the large peaks in closed loop response. This facts reveals that the compensator is useful to operate the system with smooth transients. Finally, the designed low pass filter allows to operate the system taking into account the device limits and achieving a smooth time response similar to a first order response without overshoot. Finally, the stability of the closed loop system is discussed considering the Gain margin and Phase margin with the controller $K(s)$ that includes: PI+compensator+LP filter. Fig. 16 shows the frequency response of the transfer function $G K(s)$ and their margins. Both margins are positive, ensuring stability of the system with the designed controller. Controller parameters are illustrated in Table IV for both pairs.

Bode Diagram
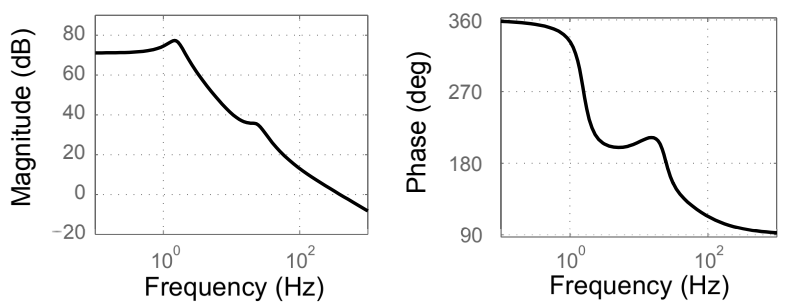

Fig. 11. Bode diagram representation of the open loop transfer function $G(s)$

\section{Simulation Results With 3-TERMinAl GRID}

In this section, simulation results for the CFC and the 3terminal grid are presented. The linearised average model of 


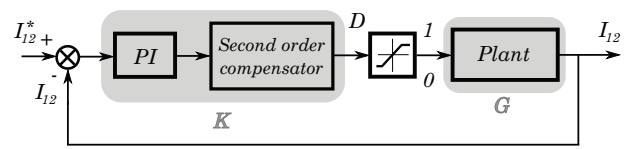

Fig. 12. Line current control scheme.

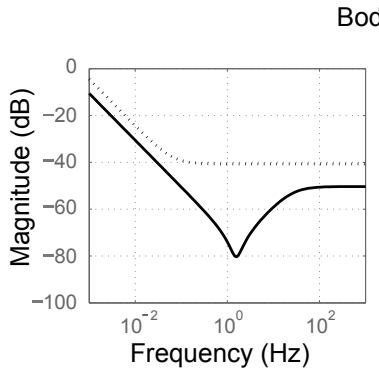

Bode Diagram

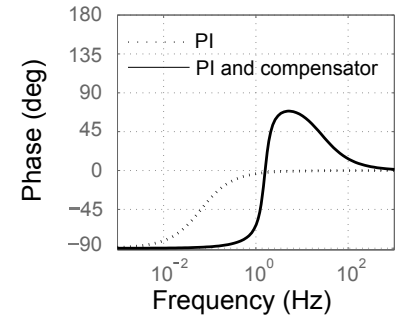

Fig. 13. Bode diagram representation of the controller transfer function $K(s)$ Bode Diagram

$$
\mathrm{PI} \quad--\mathrm{PI}+\mathrm{C}---\mathrm{T}=0.01-\mathrm{T}=0.03
$$$$
++T=0.05 \quad \times \times T=0.1
$$
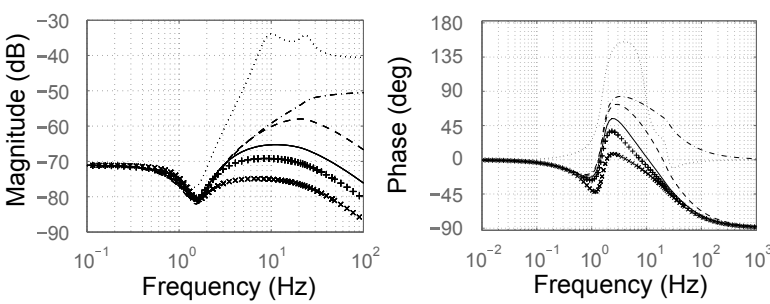

Fig. 14. Bode diagram representation of transfer function $K S(s)$

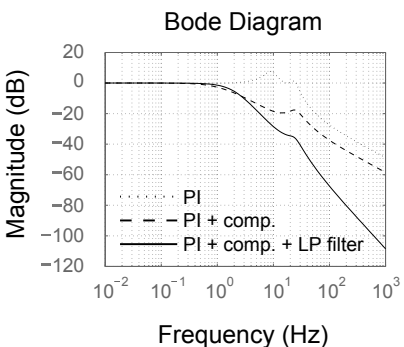

(a)

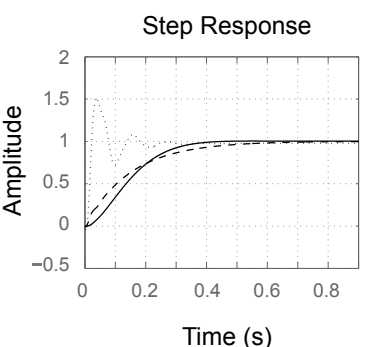

(b)
Fig. 15. Frequency and time response of the closed loop transfer function Bode Diagram

$\mathrm{Gm}=34.5 \mathrm{~dB}($ at $18.6 \mathrm{~Hz}), \mathrm{Pm}=72.1 \mathrm{deg}($ at $1.01 \mathrm{~Hz})$

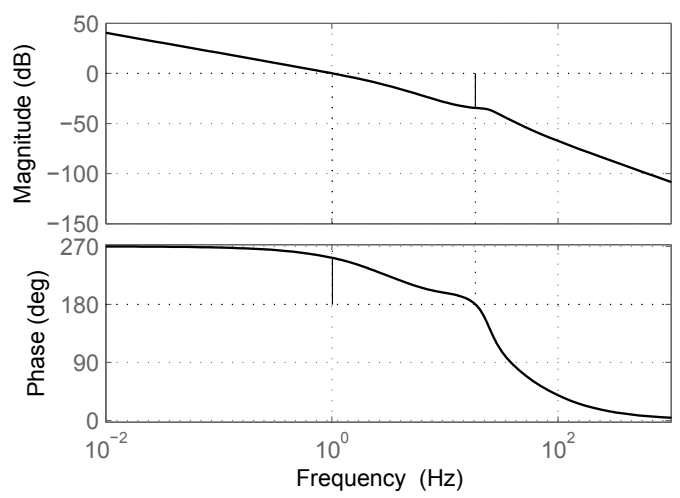

Fig. 16. Frequency response of the transfer function $G K(s)$

the $\mathrm{CFC}$, which is represented by a couple of voltage sources is compared with the switching one (composed of 6 IGBTs as shown in Fig. 2b). Two scenarios are addressed, whose parameters are depicted in table V and table VI. The black lines of the graphics are the variables of the switching model of the CFC, whereas the grey lines are the variables of the
TABLE V

3-TERMINAL SYSTEM PARAMETERS

\begin{tabular}{|c|c|c|c|}
\hline \multicolumn{4}{|c|}{ DC cable parameters } \\
\hline & Line 12 & Line 13 & Line 23 \\
\hline Distance $[\mathrm{km}]$ & 100 & 200 & 200 \\
\hline Resistance $[\Omega / \mathrm{km}]$ & \multicolumn{3}{|c|}{0.0095} \\
\hline Inductance $[\mathrm{mH} / \mathrm{km}]$ & \multicolumn{3}{|c|}{2.111} \\
\hline Capacitance $[\mu \mathrm{F} / \mathrm{km}]$ & \multicolumn{3}{|c|}{2.104} \\
\hline Conductance $[\mu \mathrm{S} / \mathrm{km}]$ & \multicolumn{3}{|c|}{0.062} \\
\hline Nominal current $[\mathrm{kA}]$ & \multicolumn{3}{|c|}{2} \\
\hline \multicolumn{4}{|c|}{ Converter terminal parameters } \\
\hline Nominal voltage $[\mathrm{kV}]$ & \multicolumn{3}{|c|}{ \pm 200} \\
\hline Nominal power [MW] & \multicolumn{3}{|c|}{1600} \\
\hline Capacitance $[\mu \mathrm{F}]$ & \multicolumn{3}{|c|}{450} \\
\hline \multicolumn{4}{|c|}{ CFC parameters } \\
\hline Nominal voltage $[\mathrm{kV}]$ & \multicolumn{3}{|c|}{4} \\
\hline Switching frequency $[\mathrm{kHz}]$ & \multicolumn{3}{|c|}{2} \\
\hline Capacitor $[\mathrm{mF}]$ & \multicolumn{3}{|c|}{10} \\
\hline
\end{tabular}

TABLE VI

NODE PARAMETERS FOR SCENARIO 1 AND 2

\begin{tabular}{|c||c|c|c|c|c|}
\hline & $k_{2}[\mathrm{~A} / \mathrm{V}]$ & $k_{3}[\mathrm{~A} / \mathrm{V}]$ & $P_{1}[\mathrm{MW}]$ & $E_{2}^{*}[\mathrm{kV}]$ & $E_{3}^{*}[\mathrm{kV}]$ \\
\hline Scenario 1 & 0.075 & 0.05 & 1400 & 165 & 165 \\
\hline Scenario 2 & 0.05 & 0.05 & 600 & 170 & 170 \\
\hline
\end{tabular}

average model that has been linearised.

\section{A. Scenario 1}

The first scenario considers the DC system operating at $0.875 \mathrm{pu}$ of nominal power. As a result, the current through one line cable is exceeding the maximum value. The CFC is used to drive part of this current through another cable allowing the operation of the whole system under such conditions. Fig 17 shows the system variables. At instant $t=0.5$ $\mathrm{s}, I_{12}$ is reduced to keep the system operating inside the maximum rating of the cables and the rest of the current goes through cable 13. At instant $t=2 \mathrm{~s}, I_{12}$ is again reduced to show the possibilities of the device. Node voltages suffer small variations due to the CFC device operation. Simulation results show that the duty cycle is reduced since a portion of current through cable 12 is driven through cable 13. Capacitor voltage is positive, however the voltage applied by the device is negative. Pair B is used for this scenario.

\section{B. Scenario 2}

The second scenario considers the system operating at 0.375 pu of nominal power. In this case the CFC is used to null the current through one of the line cables. Fig 18 depicts the system variables. At instant $t=0.5 \mathrm{~s}$, CFC is used to reduce $I_{13}$ to $0 \mathrm{~A}$, what is equivalent to lead all the current coming from node 1 through cable 12 . At instant $t=2 \mathrm{~s}$, the device allows again the current flow through line 13. In this case, duty cycle increases when $I_{13}$ is reduced. Capacitor voltage and the voltage applied by the CFC are both positive as the device is working with pair A. Voltage of node 1 shows small divergence between the linearised model and the detailed one, the reason is that equation (13) is highly non-linear compared to equations of other nodes which are performing droop control.

\section{Simulation RESUlts With 5-TERMinal GRID}

In this section a more complex HVDC is considered. The same control procedure is applied to a meshed 5-terminal 

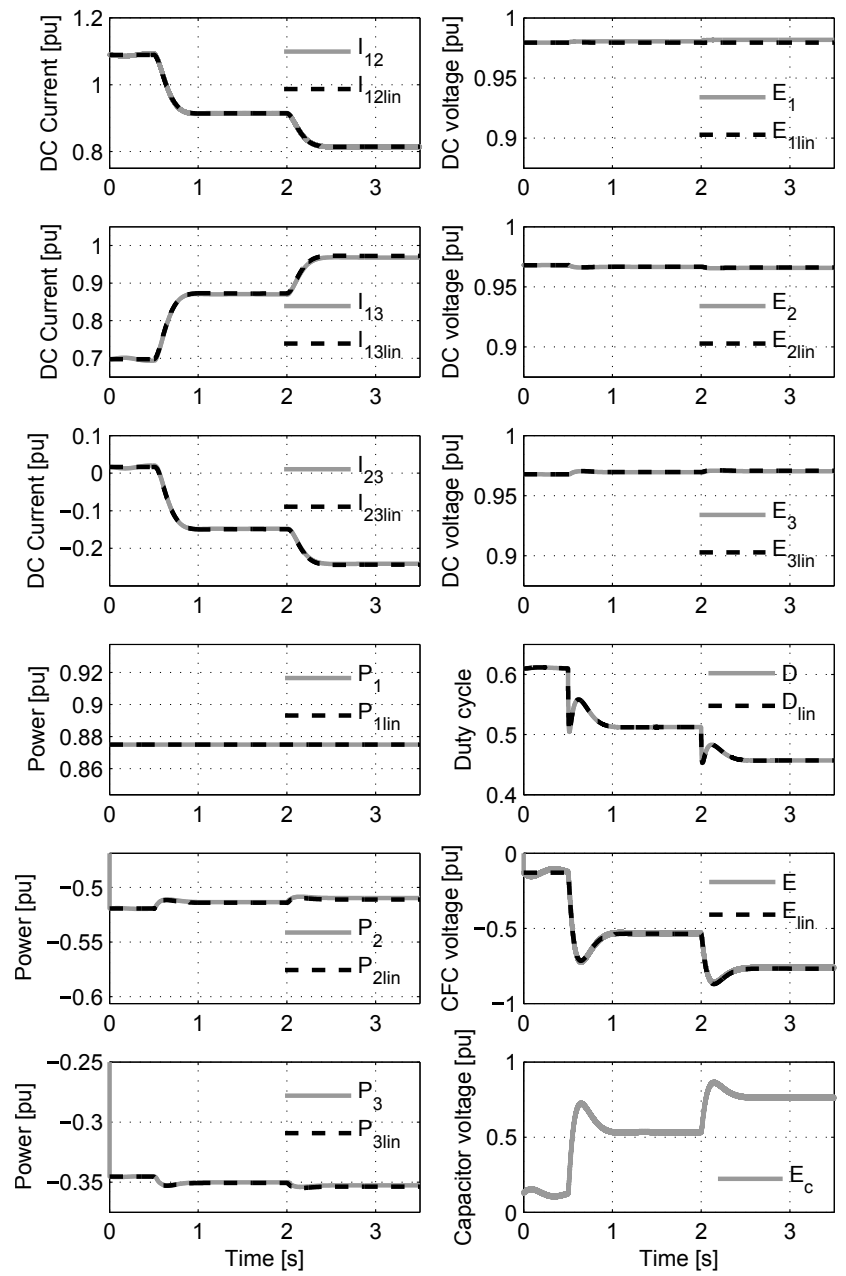

Fig. 17. Scenario 1: Line currents, node voltages, node powers, duty cycle, CFC voltage and capacitor voltage.

TABLE VII

5-TERMINAL SYSTEM PARAMETERS

\begin{tabular}{|c||c|c|c|c|c|c|c|}
\hline \multicolumn{7}{|c|}{ DC cable parameters } \\
\hline Lines & 23 & 21 & 31 & 34 & 41 & 45 & 51 \\
\hline Distance $[\mathrm{km}]$ & 100 & 80 & 120 & 100 & 100 & 120 & 80 \\
\hline \multicolumn{7}{|c|}{ Converter terminal parameters } \\
\hline Nodes & 1 & 2 & 3 & 4 & 5 \\
\hline Capacitance $[\mu \mathrm{F}]$ & 300 & 300 & 150 & 150 & 450 \\
\hline Power $[\mathrm{MW}]$ & - & 800 & - & -200 & -1200 \\
\hline$E_{i}^{*}[\mathrm{kV}]$ & 200 & - & 200 & - & - \\
\hline Droop constant $k_{i}[\mathrm{~A} / \mathrm{V}]$ & 0.05 & - & 0.05 & - & - \\
\hline
\end{tabular}

HVDC grid. The state space model is linearised and the CFC controller is tuned following the same strategy than in section IV. The 5-terminal grid scheme with the CFC in node 1 is depicted in Fig. 19. The grid parameters are illustrated in Table VII. The following simulations are performed considering average models for converter terminals and switching model for the CFC. Two scenarios are simulated.

\section{A. Scenario 3: Power step change}

In scenario 3 , the controlled current is $I_{41}$. At instant $1 \mathrm{~s}$, a reference change of $-200 \mathrm{~A}$ is introduced into the controller (Fig. 20). The system achieves a first order transient response. A power step change of $-200 \mathrm{MW}$ is applied in terminal 5, at instant $3 \mathrm{~s}$, while the current reference for $I_{41}$ is kept the same. The system suffers some oscillations after the power change, however, the CFC is able to maintain the current $I_{41}$
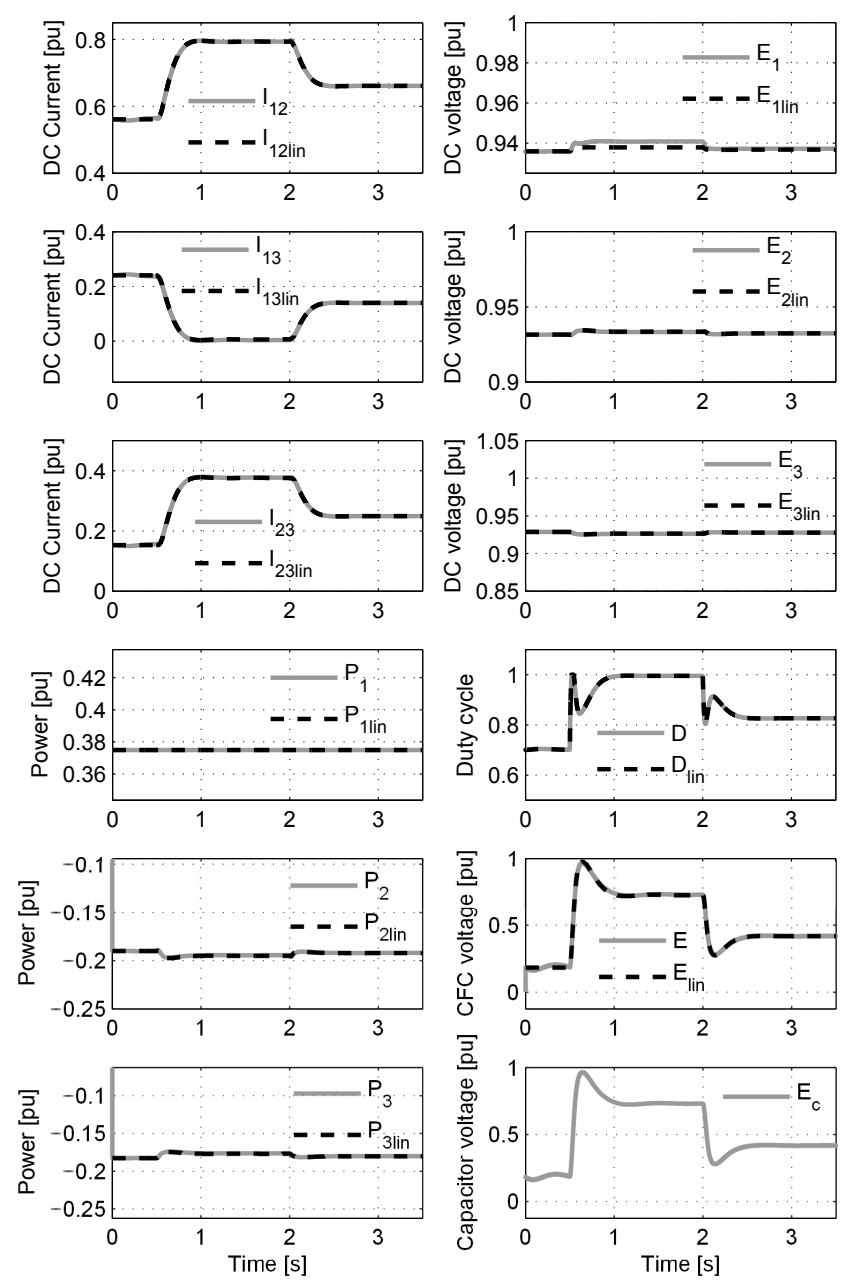

Fig. 18. Scenario 2: Line currents,node voltages, node powers, duty cycle, CFC voltage and capacitor voltage.

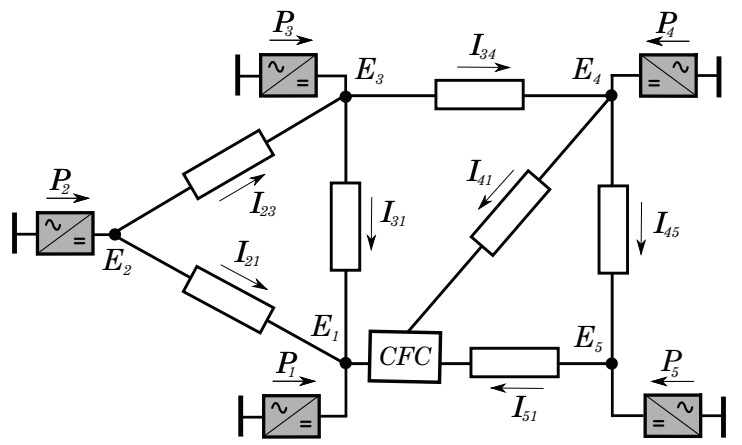

Fig. 19. 5-terminal DC grid with the CFC in node 1.

to the same value after a transient of some seconds. The CFC voltage in the capacitor has also some oscillations while trying to maintain the same current through line 41 .

\section{B. Scenario 4: Terminal outage}

In scenario 4 , the controlled current is also $I_{41}$. At instant $1 \mathrm{~s}$, a reference change of $-700 \mathrm{~A}$ is introduced into the controller (Fig. 21). The CFC is able to achieve the desired current with a smooth response. A terminal outage happens in node 2 while the current reference for $I_{41}$ is kept the same. Power of node 2 goes to 0 and the whole system suffers important oscillations. A few seconds later, the CFC is able to regulate $I_{41}$ to the same level as before. The CFC voltage 

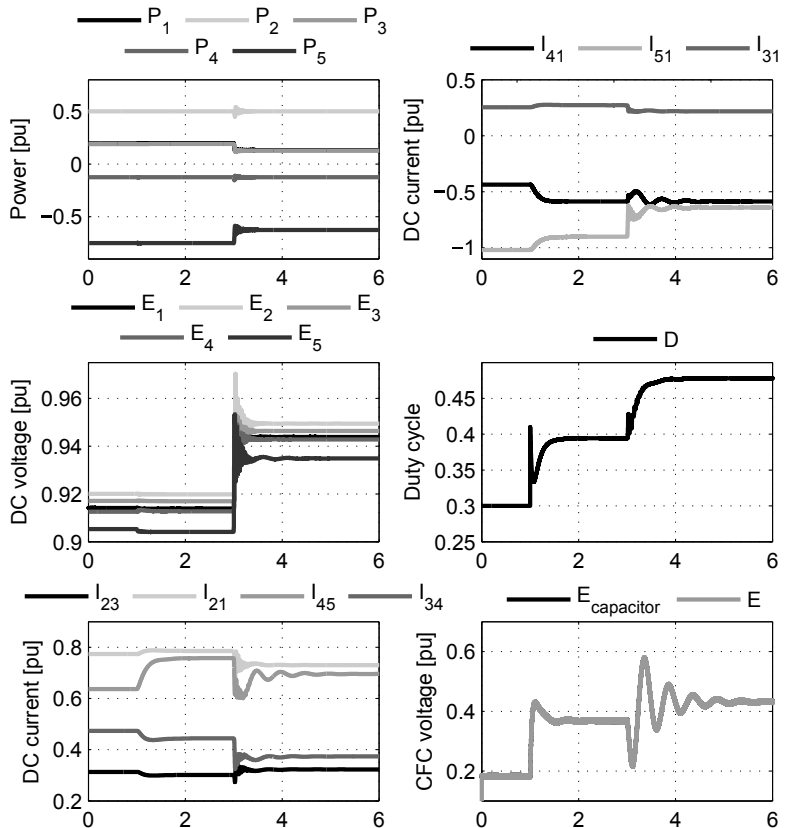

Fig. 20. Scenario 3: System variables under a power step change.

and duty cycle experiment also transient oscillations due to the converter outage.
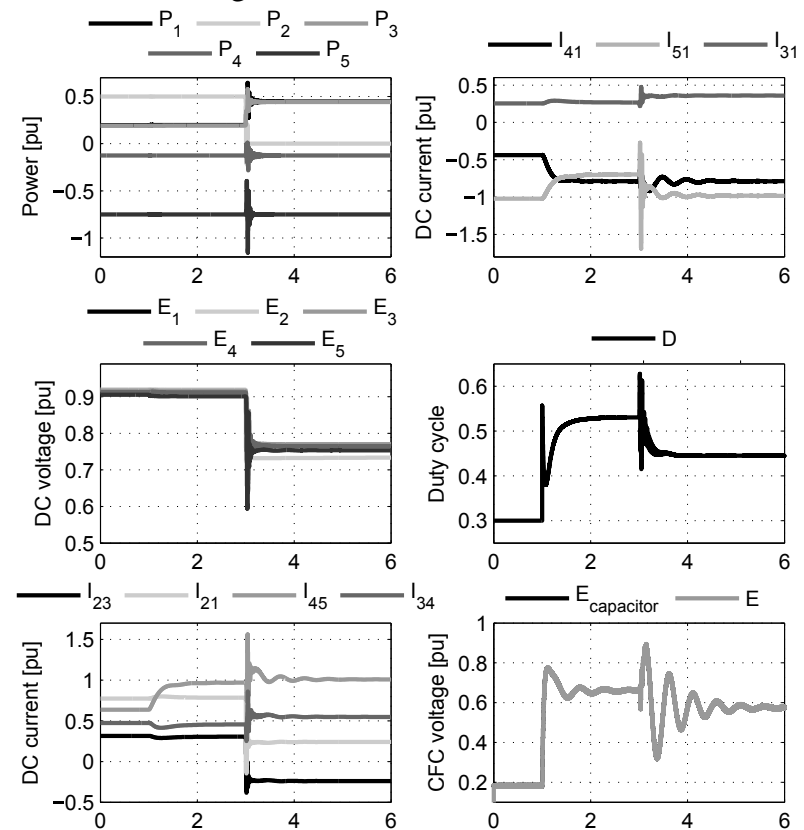

Fig. 21. Scenario 4: System variables under a converter terminal outage

\section{CONCLUSION}

In this paper an interline DC/DC CFC has been analysed. The different operation states of the converter have been gathered in pairs in order to apply voltages on the lines with the minimum number of active switches. Then an average model of the CFC is derived and it is used to perform steady-state analysis in a 3-terminal HVDC grid. Changing the duty cycle of the active switch of the CFC allows varying significantly the line current relation. It also shows that with few $\mathrm{kV}$ in the CFC capacitor, several hundreds of amperes can be redirected. The operation area of the system with and without CFC has been illustrated. This operation area shows an important increase and this analysis also provides a criterion to choose the voltage rating of the $\mathrm{CFC}$. Control strategy has been proposed based on the linearised model of the meshed DC grid and the CFC. Dynamic simulations show good performance during step changes in the CFC reference. Besides, the linearised model and the detailed model of the grid and the CFC show close similarity, giving additional validation to the control approach. Finally, the control design is also addressed for a meshed 5terminal HVDC grid and validated through simulation. The system performance is tested considering CFC reference step changes, node power changes and a terminal outage. The CFC shows acceptable performance under such conditions validating the control procedure for a more complex HVDC grid.

\section{REFERENCES}

[1] Wind energy scenarios for 2020, European Wind Energy Association (EWEA). Jul. 2014.

[2] N. Kirby, L. Xu, M. Luckett and W. Siepmann, "HVDC transmission for large offshore wind farms," in 7th Int. Conf. on AC-DC Power Transmission, 2001, pp 162-168.

[3] M. Bahrman and B. Johnson, The ABCs of HVDC transmission technology, IEEE Power Energy Mag., vol. 5, no. 2, pp. 32-44, Mar./Apr. 2007.

[4] O. Gomis-Bellmunt, J. Liang, J. Ekanayake, R. King and N. Jenkins. "Topologies of multiterminal HVDC-VSC transmission for large offshore wind farms", Electric Power Systems Research, vol. 81, issue 2, pp. 271281, Feb. 2011.

[5] A. Egea-Alvarez, F. Bianchi, A. Junyent-Ferre, G. Gross and O. GomisBellmunt, "Voltage Control of Multiterminal VSC-HVDC Transmission Systems for Offshore Wind Power Plants: Design and Implementation in a Scaled Platform", IEEE Trans. Ind. Electron., vol. 60, issue 6, pp. 2381-2391, Jun. 2013.

[6] M. Aragues-Penalba, A. Egea-Alvarez, O. Gomis-Bellmunt and A. Sumper. "Optimum voltage control for loss minimization in HVDC multiterminal transmission systems for large offshore wind farms", Electric Power Systems Research, vol. 89, pp. 54-63, Aug. 2012.

[7] M. Bucher, R.Wiget, G. Andersson, and C. Franck, Multiterminal HVDC networks. What is the preferred topology? IEEE Trans. Power Del., vol. 29, no. 1, pp. 406-413, Feb. 2014.

[8] E. Veilleux and B. Ooi, Power flow analysis in multi-terminal HVDC grid, in Power Systems Conf. and Expo. (PSCE), 2011, pp. 1-7.

[9] Q. Mu, J. Liang, Y. Li and X. Zhou, Power flow control devices in DC grids, in Power and Energy Society General Meeting IEEE, 2012, pp. $1-7$.

[10] D. Jovcic, M. Hajian, H. Zhang and G. Asplund, Power flow control in DC transmission grids using mechanical and semiconductor based DC/DC devices, in in IET Int. Conf. on AC and DC Power Transmission (ACDC), 2012, pp. 1-6.

[11] D. Jovcic and B. Ooi, Developing DC transmission networks using DC transformers, IEEE Trans. Power Del., vol. 25, no. 4, pp. 2535-2543, Oct. 2010.

[12] E. Veilleux and B. Ooi. Multi-terminal HVDC with thyristor power-flow controller, IEEE Trans. Power Del. , vol. 27, no. 3, pp. 1205-1212, Jul. 2012.

[13] S. Balasubramaniam, J. Liang and C.E. Ugalde-Loo, "An IGBT based series power flow controller for multi-terminal HVDC transmission," in 49th Int UPEC, Cluj-Napoca, 2014, pp. 1-6.

[14] C. Barker and R. Whitehouse, A current flow controller for use in HVDC grids, in IET Int. Conf. on AC and DC Power Transmission (ACDC), 2012, pp. 1-5.

[15] W. Chen, X. Zhu, L. Yao, X.Ruan, Z. Wang and Y. Cao, An Interline DC Power Flow Controller (IDCPFC) for Multi-terminal HVDC System, IEEE Trans. Power Del. vol. 30, issue 4, pp. 2027-2036, Aug. 2015.

[16] N. Deng, P. Wang, X. Zhang, G. Tang and J. Cao, ”A DC current flow controller for meshed modular multilevel converter multiterminal HVDC grids," CSEE Journal of Power and Energy Systems, vol.1, no.1, pp. 4351, Mar. 2015.

[17] T. K. Vrana, S. Dennetiere, J. Jardini, Y. Yang, and H. Saad, The CIGRE B4 DC grid test system version 2013, in Electra, Mar. 2013. 
[18] E. Prieto-Araujo, A. Egea-Alvarez, S. Ferkiasl and O. Gomis-Bellmunt, "DC voltage droop control design for multi-terminal HVDC systems considering AC and DC grid dynamics", IEEE Trans. Power Del., accepted for publication.

[19] E. Prieto-Araujo, F. Bianchi, A. Junyent-Ferre, O. Gomis-Bellmunt, "Methodology for droop control dynamic analysis of multiterminal VSCHVDC grids for offshore wind farms", IEEE Trans. Power Del., vol. 26, no. 4, pp. 2476-2485, Oct. 2011.

[20] P. Apkarian and D. Noll, "Nonsmooth H-infinity Synthesis". IEEE Trans. on Automat. Contr., vol. 51, no. 1, pp. 71-86, 2006.

[21] The control handbook, William S. Levine, CRC Press, 1996.

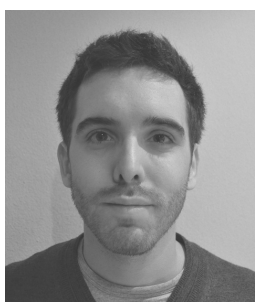

Joan Sau-Bassols (S'14) received the degree in Industrial Engineering from the School of Industrial Engineering of Barcelona (ETSEIB), Technical University of Catalonia (UPC), Barcelona, Spain, in 2014, where he is currently pursuing the Ph.D. degree in Electrical Engineering. Since 2012, he has been with the Centre d'Innovació Tecnològica en Convertidors Estàtics i Accionaments, (CITCEAUPC). His research interests include renewable generation systems, HVDC transmission systems, HVDC grids, current flow control and DC/DC con-

verters.

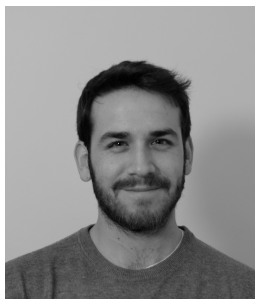

Eduardo Prieto-Araujo (S'12) received the degree in Industrial Engineering from the School of Industrial Engineering of Barcelona (ETSEIB), Technical University of Catalonia (UPC), Barcelona, Spain, in 2011, where he is currently pursuing the Ph.D. degree in Electrical Engineering. Since 2010, he has been with the Centre d'Innovació Tecnològica en Convertidors Estàtics i Accionaments, (CITCEAUPC). His research interests include the modeling and control of electrical machines, renewable generation systems, microgrids and control of power electronic converters for HVDC transmission.

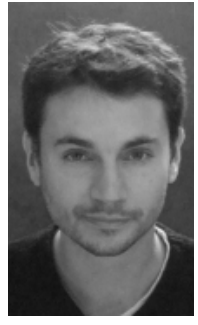

Oriol Gomis-Bellmunt (S'05-M'07-SM'12) received the degree in industrial engineering from the School of Industrial Engineering of Barcelona (ETSEIB), Technical University of Catalonia (UPC), Barcelona, Spain, in 2001 and the PhD in electrical engineering from the UPC in 2007. In 1999 he joined Engitrol S.L. where he worked as project engineer in the automation and control industry. In 2003 he developed part of his $\mathrm{PhD}$ thesis in the DLR (German Aerospace center) in Braunschweig (Germany). Since 2004 he is with the Electrical Engineering Department of the UPC where he is lecturer and participates in the CITCEA-UPC research group. Since 2009 he is also with the Catalonia Institute for Energy Research (IREC). His research interests include the fields linked with smart actuators, electrical machines, power electronics, renewable energy integration in power systems, industrial automation and engineering education. 